DOI: 10.5007/2175-7941.2013v30n2p362

\title{
INSTRUÇÃO PELOS COLEGAS E ENSINO SOB MEDIDA: UMA PROPOSTA PARA O ENGAJAMEN- TO DOS ALUNOS NO PROCESSO DE ENSINO- APRENDIZAGEM DE FÍSICA ${ }^{+*}$
}

\author{
Ives Solano Araujo \\ Instituto de Física - UFRGS \\ Porto Alegre - RS \\ Eric Mazur \\ Harvard University \\ Cambridge - Massachusetts \\ EUA
}

\begin{abstract}
Resumo
Melhorar a formação profissional e acadêmica dos indivíduos nos mais diversos niveis passa por repensar o papel das estratégias formais de ensino. Em termos educacionais, pesquisa após pesquisa tem mostrado os problemas de se investir quase exclusivamente na apresentação oral dos conteúdos como estratégia didática. Seja por falta de infraestrutura para implementar novas soluções, inércia do sistema escolar ou mesmo por desconhecimento de alternativas viáveis de mudança, essa estratégia quase milenar ainda hoje é onipresente no ambiente escolar. Em sua face mais visivel, o chamado ensino tradicional está fortemente associado com a evasão escolar, a aprendizagem mecânica e a desmotivação para aprender por parte dos estudantes. Diversas são as recomendações abstratas e gerais, de cunho pedagógico, feitas aos professores para reverter esse quadro. Contudo, poucas são as alternativas
\end{abstract}

\footnotetext{
Peer Instruction and Just-in-Time Teaching: engaging students in physics learning

* Recebido: agosto de 2012.

Aceito: abril de 2013.
} 
concretas apresentadas, em especial no Ensino de Física em nível médio e nas disciplinas básicas de nível superior. Tendo em vista esse cenário, o presente artigo tem como objetivos divulgar as potencialidades do uso combinado de dois métodos de ensino, focados na aprendizagem significativa de conceitos e procedimentos; e também fornecer conselhos práticos para favorecer a implementação deles em sala de aula.

Palavras-chave: Instrução pelos Colegas. Peer Instruction. Ensino sob Medida. Just-in-Time Teaching. Ensino de Física.

\begin{abstract}
Improving one's professional and academic training on many levels requires rethinking the role of formal teaching strategies. In education time and again educational research highlights the problems associated with employing lectures almost exclusively as an instructional strategy. Whether due to the lack of infrastructure for implementing new solutions, inertia of the school system or even the lack of viable alternative choices, this ancient strategy is still ubiquitous in the school environment, regardless of the associated learning outcomes. The so-called "traditional" teaching method of lecture is strongly correlated with rote learning and the absence of students' motivation to learn. There are several abstract, general pedagogical theories about this situation that teachers may employ. However, there are few concrete alternatives to help teachers, particularly in physics at both the high school and higher education introductory level. With this in mind, we describe and encourage the combined use of two methods of teaching that are focused on meaningful learning of concepts and procedures, and we provide practical advice to facilitate their implementation in the classroom.
\end{abstract}

Keywords: Peer Instruction. Just-in-Time Teaching. Physics Education. 


\section{Introdução}

Seja por questões sociais ou de mercado, há uma demanda crescente pela formação de profissionais que tenham conhecimentos sólidos sobre conteúdos específicos e possuam habilidades e competências associadas ao trabalho colaborativo, discussão de ideias e metacognição. Escolas e universidades são as instituições nas quais se espera que essa formação aconteça, ou pelo menos seja bem encaminhada, principalmente através de ações dos professores. Tal responsabilidade não é um fardo leve. Em meio a condições não raro adversas de infraestrutura e apoio institucional, o professor tem como tarefa propiciar aos alunos condições para que possam se engajar no processo de aprendizagem e orientá-los de modo a alcançar uma aprendizagem significativa da matéria em estudo. "Tornar o aluno um agente ativo, (co)responsável pelo processo de ensino e aprendizagem" é algo mais fácil de defender do que colocar em prática, principalmente quando o professor está à frente de uma classe numerosa, com alunos pouco interessados, sempre assombrado pelo fantasma da evasão.

No cenário internacional, algumas iniciativas para o enfrentamento desse desafio merecem destaque por terem conseguido modificar, com sucesso, a dinâmica de sala de aula e alcançado, sistematicamente, resultados positivos tanto na aprendizagem conceitual de conteúdos científicos quanto no desenvolvimento de habilidades cognitivas e sociais (CROUCH; MAZUR, 2001; CROUCH et al., 2007; JAMES, 2006; TURPEN; FINKELSTEIN, 2009, 2010). Mais especificamente, nos referimos aos métodos ativos de ensino Peer Instruction e Just-in-Time Teaching, em uma tradução livre Instrução pelos Colegas (IpC) e Ensino sob Medida (EsM). O primeiro vem sendo desenvolvido desde a década de 90 do século passado pelo Prof. Eric Mazur da Universidade de Harvard (EUA) (MAZUR, 1997), coautor do presente trabalho. O método vem sendo amplamente aplicado em diversas escolas e universidades em todo o mundo. De modo geral, o IpC busca promover a aprendizagem com foco no questionamento para que os alunos passem mais tempo em classe pensando e discutindo ideias sobre o conteúdo, do que passivamente assistindo exposições orais por parte do professor.

O segundo método foi elaborado pelo professor Gregor Novak da Universidade de Indiana (EUA) e colaboradores, em 1999 (NOVAK et al., 1999). Apesar de não ser tão conhecido quanto o primeiro, vem se mostrando uma excelente opção para levar em consideração o conhecimento prévio dos alunos na elaboração de aulas que enderecem dificuldades específicas da turma para a qual se destina. Além disso, esse método tem se mostrado efetivo para formar o hábito de estudo antes das aulas, por parte dos alunos. O foco do EsM está na criação de 
condições para que o professor possa preparar suas aulas a partir das dificuldades manifestadas pelos próprios alunos. Essas dificuldades são mapeadas em uma etapa preparatória, preliminar à aula, na qual eles são convidados a estudar os materiais fornecidos pelo professor e a fornecer respostas que permitam avaliar o grau de compreensão alcançado sobre os conteúdos. Ambos os métodos serão discutidos em maior detalhe nas seções seguintes.

Esses métodos de ensino têm sido pouco utilizados no Brasil e mostramse desconhecidos da grande maioria dos professores com os quais entramos em contato em palestras e cursos de formação. No presente trabalho, temos como objetivo promover uma maior divulgação desses métodos e com isso fornecer aos professores, em especial do nível médio, estratégias úteis para tentar qualificar o ensino de Física no País. Apresentaremos uma proposta para organização do ensino de Física que envolve o uso do IpC combinado com o EsM, conforme proposto por Mazur e Watkins (MAZUR; WATKINS, 2010). Nossa meta é incentivar a adoção de um modelo de ensino que valorize o tempo em sala de aula, destinandoo para a aprendizagem ativa dos conteúdos por parte dos alunos, e não quase exclusivamente para transmissão de informações.

Como exemplo da aplicação de métodos ativos de ensino, um artigo publicado na revista Science em maio de 2011 (DESLAURIERS; SCHELEW; WIEMAN, 2011) ganhou grande destaque em jornais norte-americanos e blogs na internet, tanto pelos seus resultados quanto pelo fato de um de seus autores ser um ganhador do Prêmio Nobel de Física. O artigo relata os resultados de uma pesquisa que comparou os desempenhos de dois grupos de estudantes de uma disciplina de Física Geral. Para os fins da pesquisa, os grupos se mostraram equivalentes antes da abordagem. Cada grupo teve aulas com professores de perfis distintos, aplicando metodologias de ensino diferentes, mas com os mesmos objetivos de ensino e conteúdos a ensinar. No grupo de controle, um professor experiente na disciplina em questão, e bem avaliado pelos alunos ao longo dos anos, ministrou aulas essencialmente expositivas com demonstrações experimentais e resolução de problemas exemplares. O grupo experimental teve aulas, durante o estudo, com um aluno de pós-graduação sem experiência na disciplina e que ministrou as aulas usando de forma combinada variações dos métodos IpC e EsM. Os professores entraram numa espécie de "competição" amigável para ver qual se sairia melhor. Os resultados foram todos favoráveis ao grupo experimental, tanto em termos do engajamento e frequência dos estudantes às aulas, quanto do desempenho em testes conceituais de Física. Nesse último quesito, o nível de aprendizagem do grupo experimental, estimado a partir de testes padronizados, foi maior do que o dobro do obtido pelos estudantes no grupo de controle. 
Diversos trabalhos de pesquisa vêm mostrando uma melhora no desempenho e na capacidade de resolução de problemas adquiridos por alunos de Física em nível Médio e Superior ao trabalharem com o IpC (CROUCH; MAZUR, 2001; CUMMINGS; ROBERTS, 2008; FAGEN; CROUCH; MAZUR, 2002; HAKE, 1998; LASRY; MAZUR; WATKINS, 2008) e o EsM (BELLONI; CHRISTIAN, 2003; FORMICA; EASLEY; SPRAKER, 2010; WITTMANN; THOMPSON, 2008).

No Brasil, Barros et al. (2004) elaboraram um método de engajamento interativo que incluiu a geração de mini-relatórios por parte dos alunos, o uso de tutoriais de Física Introdutória (MCDERMOTT; SHAFFER, 2001) e uma variação do método IpC. Entre outras atividades, em cada encontro de dois períodos, o professor ministrava uma aula expositiva no primeiro deles. No segundo, solicitava que os alunos trabalhassem em grupos de quatro a cinco alunos, definidos por ele no início do semestre, e respondessem questões conceituais nos moldes do IpC. Seus resultados corroboram os descritos na literatura apontando que o desempenho de estudantes envolvidos em metodologias ativas de ensino, medido por testes padronizados, no caso o FCI (Force Concept Inventory) (HESTENES; WELLS; SWACKHAMER, 1992), é superior ao desempenho obtido com métodos de ensino tradicionais, baseados fortemente em aulas expositivas.

Ainda no Brasil, Cruz, Dias e Kortemeyer (2011) relatam um estudo sobre os efeitos de uma avaliação formativa em cursos de Física de universidades brasileiras. Os autores implementaram atividades com tarefas de casa online randomizadas ${ }^{1}$ e com feedback imediato para alunos de duas universidades, uma pública e outra privada, com perfis de dedicação diferentes. A turma oriunda da instituição particular era composta por alunos que trabalhavam durante o dia e tinham aula à noite, enquanto na turma da instituição pública os alunos se dedicavam apenas aos estudos. Com essa última turma, foram também desenvolvidas atividades presenciais usando um sistema de votação eletrônico (Clickers, vide próxima seção) para que os alunos pudessem informar suas respostas para as questões apresentadas pelo professor. Uma pesquisa de opinião com os próprios alunos mostrou ampla aceitação das atividades propostas, entretanto as notas obtidas pelos alunos nas avaliações tradicionais, compostas basicamente por problemas de resolução numérica, não apresentaram melhoras. Cabe salientar que nesse trabalho, apesar do uso dos clickers e de tarefas prévias às aulas, não foram utilizados o IpC ou o EsM.

\footnotetext{
${ }^{1}$ Cada estudante tem acesso a uma versão diferente de um mesmo problema, mas com distintos valores iniciais, parâmetros, etc.
} 
Apesar de nosso foco ser a Física, é importante destacar que esses métodos vêm sendo usados com sucesso também em outras áreas tais como Biologia (CROSSGROVE; CURRAN, 2008; MARRS; NOVAK, 2004), Química (MCCREARY; GOLDE; KOESKE, 2006), Filosofia, Lógica e Pensamento Crítico (BUTCHART; HANDFIELD; RESTALL, 2009).

Na seção 2, apresentamos uma descrição mais detalhada do método IpC e, na seção 3, do EsM. Na seção 4, discutimos o uso integrado de ambos os métodos. Nas seções 5 e 6, apresentamos, respectivamente, considerações relevantes para o professor interessado em utilizar os métodos em suas aulas e outras, de cunho geral.

\section{Peer Instruction - Instrução pelos Colegas (IpC)}

De modo geral, o IpC pode ser descrito como um método de ensino baseado no estudo prévio de materiais disponibilizados pelo professor e apresentação de questões conceituais, em sala de aula, para os alunos discutirem entre si. Sua meta principal é promover a aprendizagem dos conceitos fundamentais dos conteúdos em estudo, através da interação entre os estudantes. Em vez de usar o tempo em classe para transmitir em detalhe as informações presentes nos livros-texto, nesse método, as aulas são divididas em pequenas séries de apresentações orais por parte do professor, focadas nos conceitos principais a serem trabalhados, seguidas pela apresentação de questões conceituais para os alunos responderem primeiro individualmente e então discutirem com os colegas. Mais especificamente, após uma breve exposição oral (aproximadamente 15 min.) o professor apresenta aos alunos uma questão conceitual, usualmente de múltipla escolha como a mostrada na Fig. 1, que tem como objetivos promover e avaliar a compreensão dos aprendizes sobre os conceitos mais importantes apresentados.

Cada aluno é então solicitado a pensar sobre qual a alternativa que considera correta e em uma justificativa para a sua escolha (aproximadamente $2 \mathrm{~min}$ ). $\mathrm{Na}$ sequência, é aberta a votação para mapeamento das respostas dos alunos à referida questão.

Usualmente a votação é feita por meio de algum sistema de resposta como flashcards (cartões de resposta) ou clickers, espécie de controles remotos individuais que se comunicam por radiofrequência com o computador do professor. A Fig. 2 ilustra esses instrumentos. Mais recentemente, sistemas de resposta envolvendo quaisquer dispositivos com acesso a internet, tais como notebooks, smartphones e tablets vêm se mostrando uma alternativa promissora, tanto por se valerem de 
aparelhos que os próprios estudantes já possuam, quanto por viabilizar o envio de respostas para questões abertas.
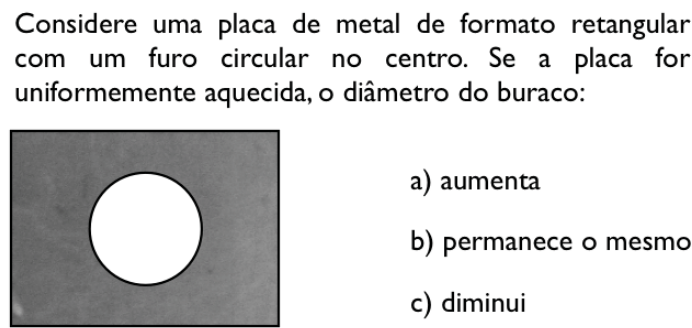

a) aumenta

b) permanece o mesmo

c) diminui

Fig. 1 - Exemplo de uma questão conceitual em Física usada no método IpC.

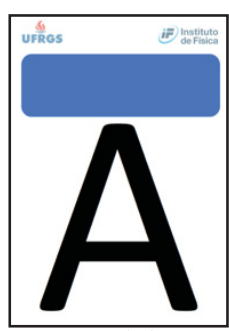

(a)

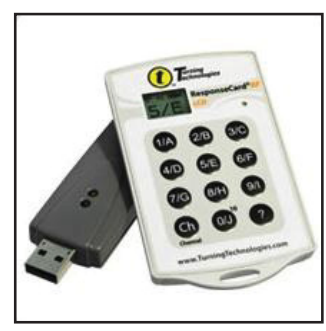

(b)

Fig. 2 - (a) Exemplo de um cartão de resposta (flashcard) com a letra "A" representando a alternativa escolhida. (b) Receptor de radiofrequência USB e sistema remoto de resposta (clicker).

Por exemplo, o aplicativo web Learning Catalytics ${ }^{2}$ permite aos estudantes traçarem em seus aparelhos a orientação de um raio de luz incidente em uma combinação de dois espelhos planos perpendiculares, conforme mostra a Fig. 3.

${ }^{2}<$ http://learningcatalytics.com> 


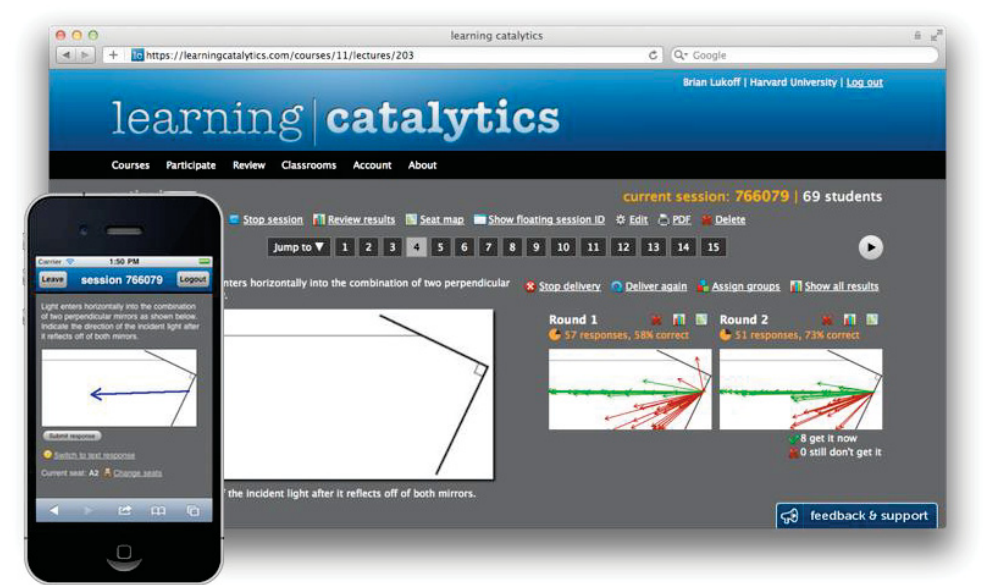

Fig. 3 - Tela ilustrativa do aplicativo web Learning Catalytics para um Teste Conceitual sobre Óptica. Na tela do smartphone o aluno visualiza o enunciado da questão e pode traçar com os dedos sua resposta (vetor em azul). Na tela de seu computador, mostrada ao fundo na figura, o professor pode visualizar a distribuição das respostas enviadas. Os vetores em verde e vermelho representam, respectivamente, as respostas corretas e incorretas submetidas pelos estudantes. $O$ próprio aplicativo faz a correção em tempo real e informa o percentual de acertos ao professor.

Com base nas respostas informadas, mas ainda sem indicar a correta aos alunos, o professor decide entre:

- explicar a questão, reiniciar o processo de exposição dialogada e apresentar um nova questão conceitual sobre um novo tópico. Essa opção é aconselhada se mais de $70 \%$ dos estudantes votarem na resposta correta;

- agrupar alunos em pequenos grupos (2-5 pessoas), preferencialmente que tenham escolhido respostas diferentes3, pedindo que eles tentem convencer uns aos outros usando as justificativas pensadas ao responderem individualmente. Após alguns minutos, o professor abre novamente o processo de votação e explica a questão. Se julgar necessário, o professor pode apresentar novas questões sobre o mesmo tópico, ou passar diretamente para a exposição do próximo tópico, reinici-

\footnotetext{
${ }^{3}$ Smith et al. (2009) apontam que há ganhos de aprendizagem, mesmo quando há discussão entre colegas, sem que um deles tenha escolhido a resposta correta previamente.
} 
ando o processo. Essa opção é aconselhada se o percentual de acertos obtidos na primeira votação estiver entre $30 \%$ e $70 \%$. O tempo despendido nesta etapa costuma ser de três a cinco minutos, dependendo do nível de discussão alcançada;

- revisitar o conceito explicado, através de nova exposição dialogada buscando aclará-lo, apresentando outra questão conceitual ao final da explanação e recomeçando o processo. Essa é a opção indicada se menos de 30\% das respostas estiverem corretas.

O diagrama mostrado na Fig. 4 ilustra o processo de aplicação do método. A parte em destaque, compreende a essência do IpC.

O IpC é um método em evolução e conta com uma comunidade ativa de professores ao redor do mundo. Para atualizações sobre seu uso e sugestões sobre melhores formas de aplicá-lo sugerimos o acesso ao seu blog oficial (em inglês): $<\mathrm{http}$ ://blog.peerinstruction.net> e também à página do Mazur Group Education ${ }^{4}$.

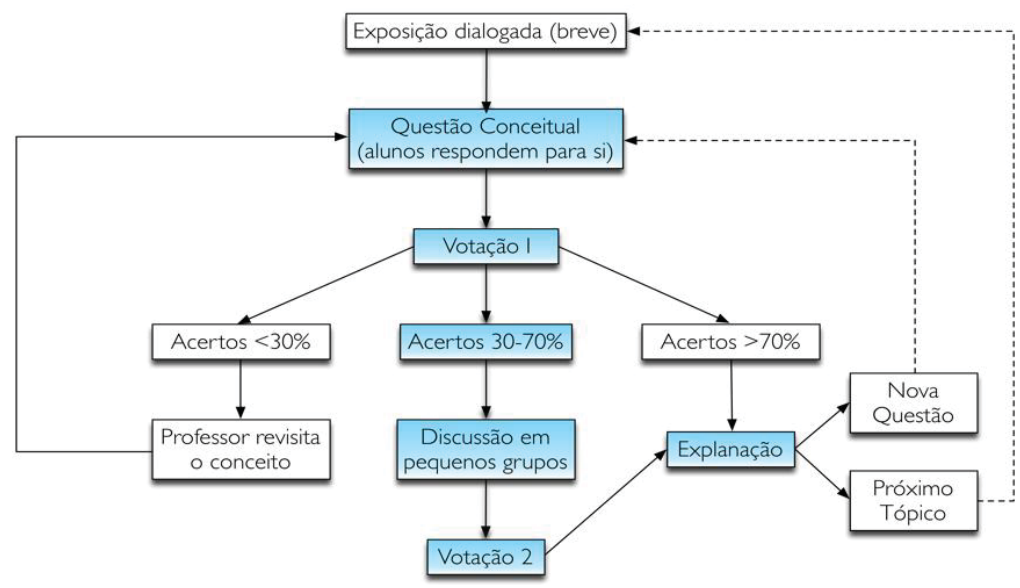

Fig. 4 - Diagrama do processo de implementação do método IpC (Peer Instruction). Em destaque, a etapa conhecida como ConcepTest. Adaptado de Lasry, Mazur e Watkins (2008).

\section{Just-in-Time Teaching - Ensino sob Medida (EsM)}

O ponto principal no EsM é a possibilidade do professor planejar suas aulas a partir dos conhecimentos e dificuldades dos seus alunos, manifestadas através

${ }^{4}<$ http://mazur.harvard.edu/education/educationmenu.php $>$. 
das respostas que eles fornecem em atividades de leitura prévias aos encontros presenciais. O JiTT envolve basicamente três etapas centradas nos alunos, apresentadas a seguir.

\section{III.1 Tarefas de Leitura (TL) sobre conteúdos a serem discutidos em aula}

Essa etapa é conhecida como "exercício de aquecimento" (WarmUp exercise) e se constitui em uma atividade de preparação prévia à aula. Nela o professor solicita que os alunos leiam materiais de apoio (e.g. algum capítulo de livro-texto, artigos curtos na internet) e logo após respondam eletronicamente (e.g. via email

ou postagens no Moodle ${ }^{5}$ ) algumas questões conceituais sobre os tópicos. O prazo máximo de envio é estipulado pelo professor e precisa ser suficiente para que ele possa preparar sua aula a partir das respostas fornecidas. O texto indicado para a leitura deve, na medida do possível, relacionar os tópicos em estudo com atividades de potencial interesse do aluno e/ou que façam parte do seu dia a dia.

Os exercícios de aquecimento têm como objetivos promover o pensamento crítico sobre o texto lido, introduzir o que será trabalhado em aula e estimular os alunos a elaborem argumentações, expressas em suas próprias palavras, para embasar suas respostas. É aconselhável que as questões sejam avaliadas com base no esforço demonstrado para o desenvolvimento de uma argumentação coerente e não em seu grau de correção.

\subsection{Discussões em sala de aula sobre as TL}

Assim que é encerrado o período de submissão de respostas à TL, elas ficam à disposição do professor para que, conforme dito anteriormente, ele as use como base para a elaboração de aulas sob medida para seus alunos. Esse feedback permite que o docente prepare explicações e escolha atividades de ensinoaprendizagem que possam auxiliar o entendimento dos conteúdos e a superação das principais dificuldades apresentadas pelos alunos.

Em sala de aula, o professor reapresenta as questões da TL e transcreve algumas das respostas dos alunos, escolhidas cuidadosamente pelo seu potencial de servir como "estopim" para a discussão em classe. Para evitar constrangimentos, o autor não deve ser identificado e tampouco pode haver qualquer comentário ou

\footnotetext{
5 O Moodle (http://moodle.org) é um ambiente de aprendizagem virtual gratuito usado mundialmente para a realização de cursos virtuais a distância e/ou como ferramenta de apoio a disciplinas presenciais.
} 
tom jocoso. É importante que o aluno se sinta confortável em expressar suas ideias, sofrendo, o mínimo possível, as pressões dos pares. Por outro lado, conforme apontam Formica, Easley e Spraker (2010), é comum que os estudantes que tiveram suas respostas selecionadas sintam-se motivados a participar mais intensamente das discussões. Nesse período de diálogo, aconselha-se que o professor traga para o debate argumentações alinhadas com concepções alternativas sobre os conceitos discutidos, visando mostrar porque elas não se sustentam. Conhecendo antecipadamente as principais dificuldades dos estudantes, o professor pode lançar mão de recursos instrucionais que auxiliem sua explicação, no exato momento em que as dúvidas vierem à tona. Como exemplos de possíveis recursos, podem ser citados: vídeos de curta duração, demonstrações experimentais, simulações computacionais, etc.

\section{III.3 Atividades em grupo envolvendo os conceitos trabalhados nas Tarefas de Leitura e na discussão em aula}

Novak e Middendorf (2004) ressaltam que a decisão de como investir o restante do tempo em sala de aula dependerá de uma série de fatores, tais como o número de alunos, a infraestrutura disponível e até mesmo das personalidades do professor e dos estudantes. O ponto principal para promover o engajamento dos estudantes durante a aula é que haja mudança nas atividades que realizam. As exposições orais devem ser curtas (aproximadamente 10min) e intercaladas com outras atividades individuais ou colaborativas, tais como discussões em aula, exercícios de fixação ou trabalhos do tipo "mão na massa" como aqueles realizados nos laboratórios didáticos de Física. Isso permite que o aluno renove sua atenção a cada mudança e também pratique o uso dos novos conceitos estudados, melhorando sua capacidade de armazenar e reter as informações discutidas.

Após as aulas os estudantes recebem outros tipos de questões para responder eletronicamente. Elas são chamadas de Puzzles (quebra-cabeças) e estão relacionadas ao conteúdo trabalhado em aula. Apresentando uma questão intrigante, que envolva um contexto diferente daquele em que o conhecimento foi discutido, o professor pode avaliar quanto o aluno está sendo capaz de transformá-lo para dar conta de novas situações. 


\section{Uso integrado dos métodos Ensino sob Medida (EsM) e Instrução pelos Colegas (IpC)}

Sob o ponto de vista do ensino, ambos os métodos podem ser usados em separado, mas seu uso conjunto parece ser a melhor opção quando existem condições básicas para implementá-los. Aqueles familiarizados com a Teoria da Aprendizagem Significativa de Ausubel (AUSUBEL, 2010) e a Teoria Sociointeracionista de Vygotsky (VYGOTSKY, 2003) devem ter percebido o quanto esses métodos mostram uma forma concreta de viabilizar ideias centrais dessas teorias.

A título de exemplificação, no que diz respeito ao EsM, o fato de o professor receber as respostas dos estudantes antes de sua aula, e poder prepará-la de acordo, vai diretamente ao encontro do que Ausubel destaca como princípio educativo mais importante:

"Se eu tivesse que reduzir toda a psicologia educacional a um único princípio, diria isto: o fator singular que mais influencia a aprendizagem é aquilo que o aprendiz já conhece. Descubra isso e ensine-o de acordo" (AUSUBEL, NOVAK, HANESIAN, 1980, p. 137).

O EsM operacionaliza o levantamento de dúvidas e dificuldades dos alunos permitindo que o professor possa de fato levar em conta o conhecimento prévio deles na organização do ensino. Tanto a elaboração das breves exposições orais, quanto a escolha das questões conceituais podem ser fortemente facilitadas se o professor contar com esse tipo de feedback.

O grande potencial do IpC, sob uma óptica vygotskyana, estaria na promoção de interações sociais qualificadas entre quem compartilha os significados socialmente aceitos pela comunidade científica, o professor, e os alunos, e deles entre si. Aqueles alunos que já conseguiram construir adequadamente seus conhecimentos, ou estão próximos disso, passam a auxiliar o professor negociando os significados desejados, tendo a vantagem de naturalmente se expressarem de forma mais próxima ao usual no diálogo entre seus colegas. Dessa forma, uma dinâmica de interlocução entre os alunos, que podem se revezar no papel de "parceiro mais capaz", encontra uma forma de viabilização efetiva em sala de aula.

Voltando ao uso combinado do EsM e do IpC, Mazur e Watkins (2010) salientam que a qualidade da discussão e, consequentemente, da aprendizagem gerada em episódios de ensino com o IpC, depende sobremaneira da qualidade dos Testes Conceituais apresentados aos estudantes. Para que um Teste Conceitual seja efetivo, as questões devem requerer reflexões sobre os conceitos de modo que os estudantes não consigam respondê-las meramente substituindo valores em fórmu- 
las, ou simplesmente usando a memória sobre algo que foi discutido anteriormente. Outro ponto importante é o nível de dificuldade das questões para os alunos. Tendo em mãos as respostas para as Tarefas de Leitura, antes da aula, o professor tem chance de escolher questões cujo nível de dificuldade seja adequado para a turma, podendo também implementar uma avaliação formativa acompanhando o progresso dos alunos antes, durante e depois de suas aulas.

Descrevendo resumidamente a integração dos métodos ilustrada na Fig. 5, temos como ponto inicial o professor elaborando uma Tarefa de Leitura (TL) focada nos tópicos a serem abordados em sala de aula. Em seguida, o professor envia a TL com certa antecedência (dois a sete dias antes da aula) para os estudantes. Desse momento até em torno de $12 \mathrm{~h}$ antes do início da aula, os alunos deverão ler o material indicado, responderem às questões e enviar eletronicamente suas respostas para o professor.

Conforme mencionado anteriormente, a TL consiste na indicação de um material para leitura (e.g. duas seções de um livro-texto) acompanhada de questões para avaliar o esforço despendido na tentativa de compreensão do material e obter feedback sobre as principais dúvidas e dificuldades dos alunos.

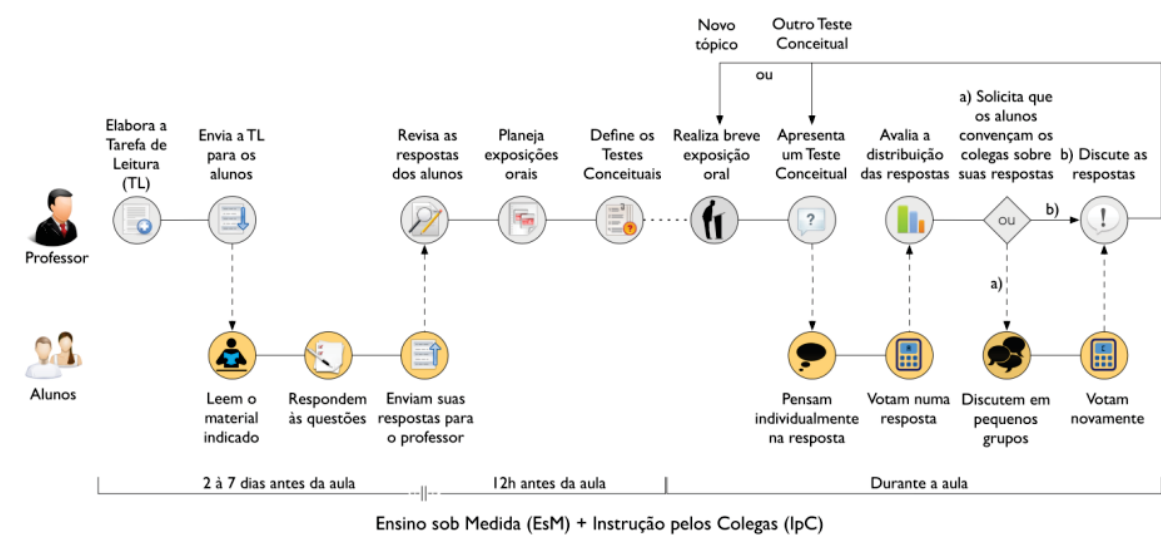

Fig. 5 - Linha de tempo do EsM e do IpC para uma determinada aula (baseado em Watkins e Mazur (2010).

Além de questões sobre o conteúdo, usualmente de uma a três perguntas, faz parte também da TL a inclusão de uma questão explícita sobre as principais dificuldades, as partes mais confusas ou interessantes do material lido, na opinião de cada aluno. Essa última questão pode ser enunciada como algo no estilo "a) 
Descreva brevemente qual(is) ponto(s) você teve mais dificuldades na Tarefa de Leitura, ou ainda o que achou confuso no material. b) Indique também os pontos que mais chamaram sua atenção. c) Sinta-se à vontade para fazer perguntas que possam auxiliar sua aprendizagem". Aconselha-se que essas tarefas recebam alguma pontuação e sejam incluídas no cômputo da nota ou conceito final a ser atribuído ao estudante, como uma forma de valorizar seu esforço preparatório.

Tendo as respostas em mãos, o professor pode revisá-las avaliando as dificuldades dos alunos e seus principais problemas de compreensão. A partir daí, cabe a ele planejar breves exposições orais para sua aula, bem como escolher (ou elaborar) Questões Conceituais que possam avaliar os resultados alcançados com sua exposição e, principalmente, fomentar discussões em sala de aula de modo a estabelecer um ambiente interativo em que os alunos pensem e discutam sobre o conteúdo, potencializando sua aprendizagem.

No início da aula, o professor pode começar com uma breve exposição oral, previamente preparada e em seguida apresentar uma questão conceitual sobre o tema. Nessa apresentação, além de projetá-la aconselha-se que o professor a leia em voz alta e busque garantir que os alunos compreenderam bem a pergunta. Após, o professor pede aos alunos que pensem individualmente nas respostas, sem interagirem uns com os outros, formulando uma argumentação que possa servir para convencer um colega que tenha marcado uma resposta diferente da sua. $\mathrm{Na}$ sequência, é solicitado aos alunos que votem na resposta que consideram correta. Nesse momento, o professor avalia a distribuição de respostas, conforme apontado na Fig. 4, e define de acordo com os resultados se os alunos devem: 1) partir para a discussão com os colegas, votar novamente e, só então, ele comenta as possíveis respostas, indicando qual é a correta e porque as outras não o são; ou 2) se vai direto para essa explicação, caminho "b)" na Fig. 5, realizando uma breve exposição oral, ainda dentro do mesmo tópico e que não seja apenas uma repetição da primeira. Nessa exposição, o professor deve buscar variar sua abordagem explicativa com elementos novos (e.g. demonstração experimental, vídeo) que deem suporte à sua argumentação e que não foram usados inicialmente. Pode-se pensar em uma "reserva estratégica" de recursos, que o professor pode trazer para a aula, mas que só lançará mão se for realmente necessário.

Supondo que a escolha feita seja pela discussão entre os alunos, ou seja, o caminho "a)" na Fig. 5, após a votação dos alunos e a explanação do professor, ele deverá avaliar, seguindo os avanços alcançados pelos estudantes, se é necessário aplicar um outro Teste Conceitual, para ter certeza de que eles compreenderam corretamente os conceitos abordados, ou se já pode passar para um novo tópico, reiniciando assim o ciclo, com outra breve exposição oral. 


\section{Alguns comentários sobre a utilização dos métodos}

Além das recomendações sobre os métodos distribuídas ao longo das seções anteriores, acrescentamos aqui alguns cuidados adicionais e/ou esclarecimentos que julgamos importantes.

Muitos professores ao tomarem contato com o IpC pela primeira vez tendem a se animar com as mudanças na dinâmica de ensino proporcionadas pela inserção do método, em especial, com o uso dos clickers. Sem dúvida o fato de poder aumentar a interação em sala de aula é algo positivo, entretanto é preciso destacar que usar os clickers não é aplicar o IpC. O ponto fundamental desse método é a interação social voltada para a aprendizagem dos conteúdos que se dá ao colocar o aluno no centro do processo educativo, atuando o professor como um facilitador dessa aprendizagem. Manter a estrutura tradicional expositiva apenas acrescentando algum sistema de votação, pode até trazer um elemento novo de motivação para os estudantes e guiar o professor na sequência de sua exposição oral, mas negligencia o ponto forte do IpC que é a promoção de um engajamento interativo em sala de aula focado no diálogo.

Ainda sobre os sistemas de votação, alguns professores, talvez por identificarem o IpC com o uso dos clickers, muitas vezes deixam de implementar o método por alegada falta de recursos técnicos para promovê-lo com seus alunos. Uma pergunta comum é "chegaremos aos mesmos resultados usando os cartões de resposta (flashcards) ao invés dos clickers?". Lasry (2008) em seus artigo intitulado "Clickers vs flashcards: existe realmente alguma diferença?" procurou uma resposta para essa pergunta comparando os resultados obtidos com a aplicação do IpC em dois grupos equivalentes de estudantes universitários que cursavam pela primeira vez uma disciplina de Física Geral. A análise do ganho normalizado para ambos os grupos, gerado a partir da aplicação do teste padronizado FCI, não mostrou diferença estatística significativa entre os dois grupos que usaram distintos sistemas de votação. Apesar de reportar que não houve diferença na aprendizagem gerada por um ou outro método, Lasry salienta que do ponto de vista do ensino, o uso dos clickers pode facilitar bastante o trabalho do professor, em especial por permitir que ele armazene os resultados das votações para análises posteriores e por dinamizar o processo de votação em sala de aula, sem que o professor precise contar os cartões em cada votação. O aplicativo que acompanha os clickers fornece um histograma da distribuição das respostas diretamente na tela do computador do professor.

Em relação a sistemas alternativos de votação, recomendamos a leitura do artigo de Müller et al. (2012) no qual é apresentado a implementação do IpC com o 
auxílio dos computadores do projeto UCA (Um Computador por Aluno), em aulas de Física do Ensino Médio, em conjunto com o recurso "formulários" do pacote de aplicativos online Google Docs.

Outro ponto que merece destaque é o cuidado que o professor deve ter ao coletar os dados da votação, em especial da primeira rodada, para que os alunos votem sem tomar conhecimento das escolhas feitas pelos colegas. Por isso, no caso da opção pelos clickers, aconselha-se que o professor não projete em tempo real as distribuições das respostas. Com os flashcards é importante que se busque minimizar as chances de um aluno esperar o outro votar, para então se manifestar. Isso pode ser alcançado através da sincronização da votação. Por exemplo, o professor pode realizar uma contagem regressiva a partir do " 3 " e pedir que, ao final, estando todos com a cabeça voltada para frente, levantem acima dela o cartão que representa a resposta de sua escolha. Seja qual for o sistema de votação, é altamente recomendável que o professor policie para não informar qual é a resposta correta antes dos alunos terem tido chances de discutir. A Fig. 6 ilustra o processo de votação em uma turma de Física no Ensino Médio.

Conforme já destacamos, o IpC tem seu foco voltado para a aprendizagem conceitual dos conteúdos. Isso fica explícito pelo papel central assumido pelos Testes Conceituais para o estabelecimento da dinâmica do método. Entretanto, aprender Física passa também pela formalização dos conceitos e, principalmente, pelo desenvolvimento de habilidades associadas à resolução de problemas quantitativos.

Apesar de pesquisas mostrarem aumento no desempenho dos alunos nesse tipo de atividade em função de uma melhora no entendimento conceitual (CROUCH et al., 2007; THACKER; KIM; TREFZ, 1994), é muito importante que o professor se planeje para incluir tais atividades em suas aulas.

Uma boa alternativa pode ser intercalar aulas de discussão conceitual usando os métodos EsM e IpC, com aulas de resolução de problemas nas quais os alunos trabalhem em pequenos grupos (de dois a três alunos) e tenham que entregar suas soluções ao final. Atividades dessa natureza também oferecem a vantagem de colocar o aluno no centro do processo educativo, permitindo que o professor auxilie na promoção do aprendizado circulando pelos grupos e tentando dirimir as dúvidas in loco, ao invés de se valer da ineficaz estratégia de resolver problemas no quadro-negro para os alunos assistirem. Na prática, se eles não tentaram de fato resolver o problema antes, ou seja, se de fato não se engajaram cognitivamente na busca por soluções antes do professor fornecer as respostas, o resultado dificilmente será outro senão o desperdício de tempo. 


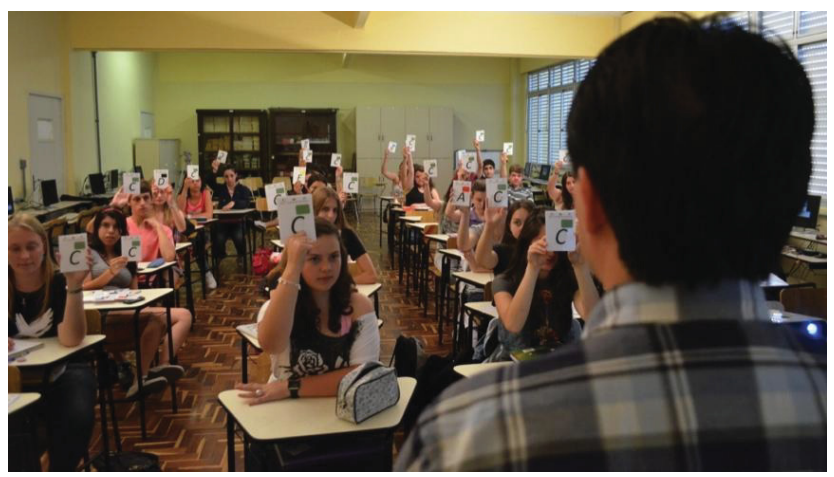

Fig. 6 - Votação em um Teste Conceitual usando flashcards em uma aula de Eletromagnetismo para o Ensino Médio do Prof. Vagner Oliveira (IFSul Campus Pelotas).

Em termos dos Testes Conceituais, em especial para o Ensino Médio, vale destacar que o professor interessado em aplicar o IpC não precisará partir do zero. Em uma procura simples em um motor de buscas como o Google por questões de vestibular e/ou do ENEM, são abundantes os resultados para praticamente todos os conteúdos de Física trabalhados. Como ponto de partida para a escolha ou mesmo elaboração de seus próprios Testes Conceituais, o professor pode contar com milhares de questões de vestibular que a comunidade acadêmica vem gerando ao longo das últimas décadas. Muitas dessas questões podem ser usadas em sala de aula diretamente, ou com pequenas modificações. Para os professores universitários, uma busca por ConcepTests ou Conceptual Tests também revelará uma quantidade enorme de resultados. O trabalho extra pode ser o de tradução para a língua portuguesa e a devida validação de conteúdo necessária para garantir que as questões traduzidas, além de compreensíveis aos alunos, tenham se mantido fiéis aos objetivos avaliativos para os quais foram designadas originalmente.

Como critério de escolha, aconselha-se procurar questões que requeiram o entendimento e aplicação dos conceitos em estudo e não questões que possam ser respondidas com base na lembrança de algo lido ou através da simples substituição de valores em fórmulas. Usualmente, os Testes Conceituais mais eficientes na promoção de discussões entre os alunos são aqueles que apresentam como possibilidade de resposta, raciocínios associados com concepções alternativas e dificuldades dos discentes sobre o conteúdo estudado (MAZUR, 1997; CROUCH; MAZUR, 2001). 
Sobre a possibilidade de atribuir notas para o desempenho nos Testes Conceituais em sala de aula, reforçamos o conselho de que essa prática seja evitada. James (2006) comparou os efeitos de pontuar apenas a participação dos estudantes nos testes com a atribuição de notas por correção das respostas e mostrou que a natureza e qualidade das discussões entre os alunos são bastante afetadas. Em situações que as respostas corretas recebem maior pontuação, os alunos com maior conhecimento sobre o conteúdo tendem a dominar as discussões e os que sabem menos assumem uma atitude passiva. A distribuição dos tempos de fala nos diálogos é fortemente afetada. Quando apenas a participação dos estudantes era considerada, as discussões se mostraram mais ricas com a maior parte dos estudantes aproveitando para exporem suas ideias e uma distribuição mais igualitária dos tempos de fala.

Em relação ao método EsM, também cabem alguns comentários. Conforme mencionado anteriormente, um dos objetivos centrais das Tarefas de Leitura está associado à criação do hábito de estudo por parte dos alunos. Para isso, o professor deve estar atento a como irá avaliar as respostas deles. Lembrando que é altamente recomendável que as questões sejam avaliadas com base no esforço demonstrado para o desenvolvimento de uma argumentação coerente, é prática comum pontuar as respostas com “2", "1" e "0". Receberá nota máxima (i.e. “2”) o aluno que apresentar argumentação que evidencie uma tentativa concreta de explicar o porquê de sua resposta, seja ela correta do ponto de vista científico ou não. $\mathrm{O}$ ponto central é fomentar a reflexão sobre o conteúdo em estudo e não avaliar o grau de correção. Se as questões de conteúdo da TL forem questões de múltipla escolha e o aluno apenas marcar uma das alternativas, sem justificar sua escolha, a nota recomendada para esse caso é " 0 ", independente da resposta estar ou não correta. A nota " 1 " aplica-se no caso intermediário em que o aluno apresenta alguns indícios de reflexão, mas não traz elementos suficientes para defender suas ideias.

Outro aspecto fundamental em relação às questões das TL é que elas não possam ser respondidas apenas "copiando e colando" o que está no material de leitura, ou ainda, como um simples exercício de memorização. Deseja-se fomentar a leitura crítica do material, logo as questões apresentadas devem demandar certa transformação do conhecimento para serem respondidas. Quanto à viabilização do envio das questões para os alunos e retorno das respostas para o professor, mais uma vez, o recurso "formulários" do Google Docs mostra-se uma alternativa atraente para o professor, seja por sua praticidade ou por sua facilidade de implementação. Para maiores informações sugerimos a leitura do trabalho de Heidemann, Oliveira e Veit (2010). 


\section{Considerações finais}

Em suas palestras sobre o IpC, o Prof. Eric Mazur costuma pedir aos participantes que fechem os olhos e pensem em algo em que se julguem realmente bons, seja lá o que for. Depois de alguns minutos ele solicita: "Levantem a mão aqueles entre vocês que construíram essa habilidade em aulas expositivas". Dificilmente alguém levanta. Se de fato as aulas expositivas não estão entre os principais fatores que nos auxiliam a desenvolver as competências e habilidades que nos são caras, o que justifica ainda o investimento maciço de tempo e energia dispensados a elas? Em parte talvez possa ser explicado por tradição. Fazia o maior sentido em outros tempos, quando as informações eram raras e o professor era, antes de mais nada, um erudito, que ele investisse em ditar ou copiar no quadro o que estava em suas anotações, ou em livros de difícil acesso. Desse modo, cada aluno seria capaz de ter uma cópia para si dos materiais.

Entretanto, o que justifica ainda esse modelo de ensino, claramente voltado para a disseminação de informações, quando poucas coisas são tão baratas e acessíveis hoje quanto a informação? Seja através da internet, de livros didáticos distribuídos gratuitamente ou de materiais fotocopiados, nunca foi tão fácil se informar. Talvez em algumas regiões carentes esse modelo, em certo grau, ainda faça sentido, mas está longe de ser o ideal naquelas que atingiram condições razoáveis de infraestrutura. Independentemente, o foco do ensino hoje deveria estar voltado para o compartilhamento e negociação de significados, sendo esse o "novo" papel do professor.

No presente artigo, apresentamos dois métodos de ensino que possuem o potencial de auxiliar o docente a estabelecer processos de ensino-aprendizagem mais frutíferos. Seus pontos fortes estão em considerar o conhecimento prévio do aluno, favorecer interações sociais voltadas para a construção do conhecimento e estabelecer as bases para o desenvolvimento de habilidades metacognitivas, começando pela criação de hábitos de estudos por parte dos alunos. Contudo, a implementação eficaz de tais métodos, assim como de qualquer inovação didática, que seja capaz de transformar a realidade em sala de aula demanda comprometimento e dedicação. Principalmente nas primeiras aplicações, o professor precisa superar o desafio de adequar o currículo, seus materiais, estratégias e avaliações para que formem uma linha de trabalho coerente. Não se pode esperar alcançar resultados diferentes, fazendo o que sempre se fez.

Muitas são as recomendações teóricas estipuladas de cima para baixo indicando dezenas de fatores que os professores precisam levar em consideração em suas aulas. Contudo, tendo em vista a complexidade da tarefa, frequentemente 
essas recomendações nada mais fazem do que aumentar a pressão sobre o professor, quando também não apontam caminhos para a sua concretização. Acreditamos aqui termos apontado alguns. De qualquer forma, um ponto precisa ficar claro: não defendemos o uso exclusivo de nenhuma estratégia de ensino, seja ela qual for. Não somos contrários a exposição dialogada em sala de aula como recurso didático, mas sim ao seu uso demasiado.

Como inspiração para o enfrentamento dos desafios para colocar em prática as necessárias tentativas de solução para os problemas do Ensino de Física em nosso País, sejam eles de ordem prática ou filosófica, finalizamos com uma célebre frase atribuída ao líder cartaginês Aníbal (247 AC-183 AC) em resposta a impossibilidades levantadas por seus seguidores:

Aut viam inveniam aut faciam

"Ou encontramos um caminho, ou abriremos um".

\section{Agradecimentos}

Agradecemos aos professores Eliane Veit (IF-UFRGS), Neusa Massoni (IF-UFRGS), Jefferson dos Santos (IFRS) e Álvaro Neves (UFV) pelas valiosas sugestões e leitura crítica do trabalho.

\section{Referências}

AUSUBEL, D. P. The Acquisition and Retention of Knowledge: A Cognitive View. [S.1.] Springer, 2010. p. 232

BARROS, J. A. et al. Engajamento interativo no curso de Física I da UFJF. Revista Brasileira de Ensino de Física, v. 26, n. 1, p. 63-69, 2004.

BELLONI, M.; CHRISTIAN, W. Physlets for quantum mechanics. 2003. p. 90 97.

BUTCHART, S.; HANDFIELD, T.; RESTALL, G. Using Peer Instruction to Teach Philosophy, Logic, and Critical Thinking. Teaching Philosophy, v. 32, p. 140, 2009.

CROSSGROVE, K.; CURRAN, K. L. Using clickers in nonmajors-and majorslevel biology courses: student opinion, learning, and long-term retention of course material. Life Sciences Education, v. 7, n. 1, p. 146, 2008. 
CROUCH, C. H. et al. Peer Instruction: Engaging students one-on-one, all at once. This volume, 2007.

CROUCH, C. H.; MAZUR, E. Peer Instruction: Ten years of experience and results. American Journal of Physics, v. 69, n. 9, p. 970, 2001.

CRUZ, É.; DIAS, H.; KORTEMEYER, G. The effect of formative assessment in Brazilian university physics courses. Revista Brasileira de Ensino de Física, v. 33 , n. 4, p. 1-7, 2011.

CUMMINGS, K.; ROBERTS, S. G. A Study of Peer Instruction Methods with High School Physics Students. AIP Conference Proceedings, v. 1064, p. 103-106, 2008.

DESLAURIERS, L.; SCHELEW, E.; WIEMAN, C. Improved Learning in a Large-Enrollment Physics Class. Science, v. 332, n. 6031, p. 862-864, 2011.

FAGEN, A. P.; CROUCH, C. H.; MAZUR, E. Peer Instruction: Results from a Range of Classrooms. The Physics Teacher, v. 40, p. 206(4), 2002.

FORMICA, S.; EASLEY, J.; SPRAKER, M. Transforming common-sense beliefs into Newtonian thinking through Just-In-Time Teaching. Physical Review Special Topics - Physics Education Research, v. 6, n. 2, p. 1-7, ago. 2010.

HAKE, R. R. Interactive-engagement versus traditional methods: A six-thousandstudent survey of mechanics test data for introductory physics courses. American Journal of Physics, v. 66, p. 64-74, 1998.

HEIDEMANN, L. A.; OlIVEIRA, Â. M.; VEIT, E. A. Ferramentas online no ensino de Ciências: uma proposta com o Google Docs. Física na Escola, v. 11, n. 2, p. 30-33, 2010.

HESTENES, D.; WELLS, M.; SWACKHAMER, G. Force Concept Inventory. The Physics Teacher, v. 30, p. 141-158, 1992.

JAMES, M. C. The effect of grading incentive on student discourse in Peer Instruction. American Journal of Physics, v. 74, n. 8, p. 689, 2006.

LASRY, N. Clickers or Flashcards: Is There Really a Difference? The Physics Teacher, v. 46, n. 4, p. 242, 2008. 
LASRY, N.; MAZUR, E.; WATKINS, J. Peer instruction: from Harvard to the two-year college. American Journal of Physics, v. 76, n. 11, p. 1066(4), 2008.

MARRS, K. A.; NOVAK, G. Just-in-Time Teaching in Biology: Creating an Active Learner Classroom Using the Internet. Cell Biology Education, v. 3, n. 1, p. 49-61, 2004.

MAZUR, E. Peer instruction: A user's manual. Pap/Dskt ed. [S.1.] Prentice Hall, Inc., 1997. p. 253

MAZUR, E.; WATKINS, J. Just-in-Time Teaching and Peer Instruction. In: SIMKINS, S.; MAIER, M. (Eds.). Just-In-Time Teaching: Across the Disciplines, Across the Academy Just-In-Time Teaching. 1. ed. Sterling: Stylus Publishing, 2010. p. 39-62.

MCCREARY, C. L.; GOLDE, M. F.; KOESKE, R. Peer instruction in the general chemistry laboratory: Assessment of student learning. Journal of Chemical Education, v. 83, p. 804-810, 2006.

MCDERMOTT, L. C.; SHAFFER, P. S. Tutorials in Introductory Physics. [S.1.] Prentice Hall College Div, 2001.

MÜLLER, M. G. et al. Implementação do método de ensino Peer Instruction com o auxílio dos computadores do projeto "UCA" em aulas de Física do Ensino Médio. Caderno Brasileiro de Ensino de Física, v. 29, n. especial, 2012.

NOVAK, G. M. et al. Just-in-time teaching: blending active learning with web technology. [S.1.] Prentice Hall, 1999. p. 188

NOVAK, G. M.; MIDDENDORF, J. What works - A Pedagogy (Just-In-Time Teaching). Disponível em:

$<$ http://www.pkal.org/documents/Vol4JiTT21stCenturyPedagogies.cfm>. Acesso em: 4 jan. 2012.

SMITH, M. K. et al. Why Peer Discussion Improves Student Performance on InClass Concept Questions. Science, v. 323, n. 5910, p. 122-124, 2009.

THACKER, B. A.; KIM, E.; TREFZ, K. Comparing problem solving performance of physics students in inquiry-based and traditional introductory physics courses. American Journal of Physics, v. 62, n. 7, p. 627-633, 1994. 
TURPEN, C.; FINKELSTEIN, N. Not all interactive engagement is the same: Variations in physics professors' implementation of Peer Instruction. Physical Review Special Topics - Physics Education Research, v. 5, n. 2, 2009.

TURPEN, C.; FINKELSTEIN, N. D. The construction of different classroom norms during Peer Instruction: Students perceive differences. Physical Review Special Topics - Physics Education Research, v. 6, n. 2, p. 020123, nov. 2010.

VYGOTSKY, L. S. Pensamento e Linguagem. São Paulo: Martins Fontes, 2003. p. 194

WITTMANN, M. C.; THOMPSON, J. R. Integrated approaches in Physics Education: A graduate level course in physics, pedagogy, and education research. American Journal of Physics, v. 76, n. 7, p. 677, 2008. 